\title{
Sensorless Speed Estimation of Permanent Magnet Synchronous Motor Using Extended Kalman Filter
}

\author{
Dr.Farazdaq R. Yasien ${ }^{1}$, Hala W. Khalid ${ }^{2}$ \\ Control and Systems Department, University of Technology, Baghdad, Iraq \\ 11drfarazdq@gmail.com,260497@student.uotechnology.edu.iq
}

\begin{abstract}
This paper presents a new approach in the modeling and the design of sensorless control method for the Permanent Magnet Synchronous Motor (PMSM) based on the use of the Extended Kalman Filter (EKF). The fourth order EKF is proposed to estimates the states: motor speed $\omega$, rotor angular position, $\theta$ and the currents from the measured currents and voltages. The linearization of the nonlinear PMSM model is done in the $\alpha \beta$ coordinate system to perform the operation of the EKF. The three phases Space Vector Pulse Width Modulation (SVPWM) inverter usually implemented as a part of the Field Oriented Control (FOC) strategy which has become a standard in the control of PMSM.
\end{abstract}

Index Terms-PMSM, EKF,SVPWM, and fuzzy like PI controller.

\section{INTRODUCTION}

The PMSM now adays have a great use in the high performance applications because these motors offer many advantages such as high efficiany, high power density, reliablity, low weight and high torque density,some of these applications are Elevators, Electric road vhichles, Pumps, and Power Factor Control.

This FOC method is a more advanced method which gives a fast transient response and a good characteristics performance.

Since we are not using the position sensors in the vector control strategy some methods such as EKF have been developed to estimate the rotor position and the motor speed. The tune of the covariance matrices of the EKF parameters can be adjusted by the trial-and-error procedures. The state equations are demonstrated by normalized state vectors based on the PMSM model.

The EKF is based on the linearizing of the state and the output equations at each sampling instant around the most recent state estimate. For this reason, this type of estimator requires computation of the Jacobian matrices.

The Vector control system structure of PMSM is shown in Fig.1 includes Fuzzy like PI controller (FLC), SVPWM inverter, EKF, and PMSM model.

The motor adopts the FOC method with closed-loop speed control scheme which compares the reference speed $\omega_{r}{ }^{*}$ with the estimated speed $\widehat{\omega_{r}}$, the resulting speed error (e) is fed into FLC that is designed by using Mamdani type. It has two inputs e and its rate $\dot{e}$ and one output. The inputs are defined as follows:

$$
\begin{aligned}
& e(k)=\omega_{r}{ }^{*}-\widehat{\omega}_{r} \\
& \dot{e}(k)=e(k)-e(k-1)
\end{aligned}
$$


The organization of this paper is as follows. Section II presents the Simulink model of the SVPWM inverter. Section III presents the structure of PMSM with mathematical model. In Section IV, we introduce the state estimation with EKF. In Section V, we show the fuzzy like PI controller design. Section VI introduces the simulation results of PMSM control system. Finally, we present meaningful conclusion.

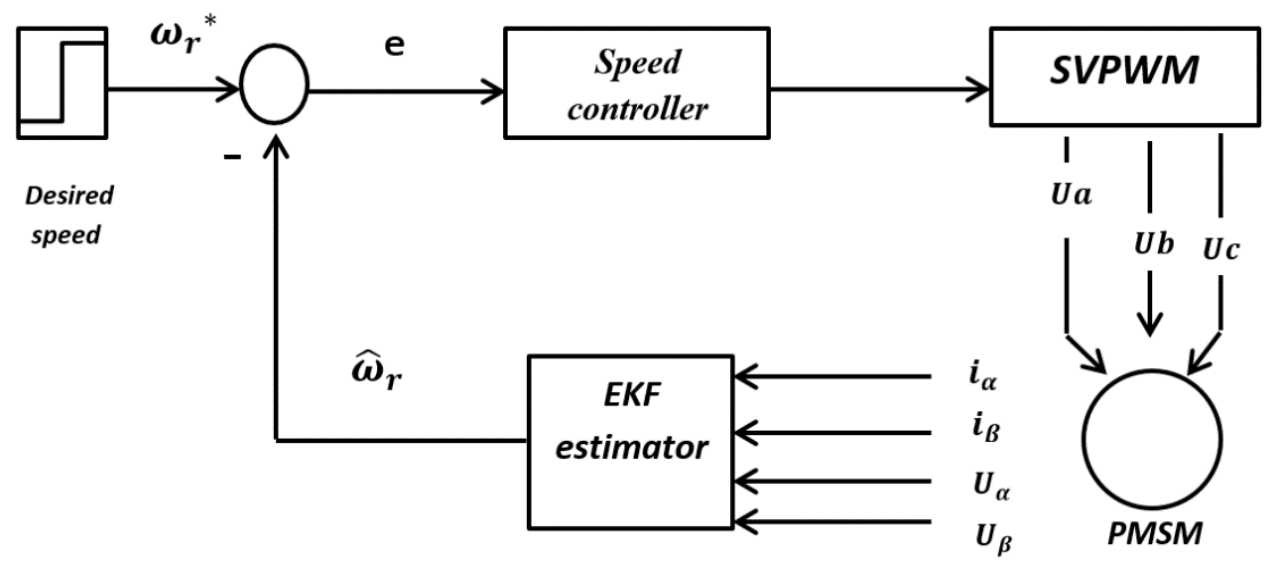

FIG. 1. BLOCK DIAGRAM OF FOC SCHEME BASED ON PMSM DRIVE.

\section{SVPWM INVERTER:}

The Pulse Width Modulation(PWM) strategies are used to generate sinsusoids of variable voltage and frequency.

The SVPWM is a better technique of the PWM implemention, it has been used as a three-phase voltage source PWM inverter feeding the PMSM . It is often used in the FOC strategy, it has 8 state vectors. The area between these vectors is devided into 6 sectors[1]. Fig. 2 shows these vectors and sectors[2].

The SVPWM technique can be implemented in three steps:

1. Determining the reference vecter $\left(\mathrm{V}_{\text {ref }}\right)$ and its angle $(\alpha)$ from the direct and quadratic vecters $\left(\mathrm{V}_{\alpha}, \mathrm{V}_{\beta}\right)$.

2. Determining the switching time duration $\mathrm{T}_{0}, \mathrm{~T}_{1}$, and $\mathrm{T}_{2}$.

3. Determining the switching time $\mathrm{S}_{1}$ to $\mathrm{S}_{6}$.

Fig. 3 shows the simulation model of the SVPWM technique were the overall model, the model for the switching time and sectors are presented.

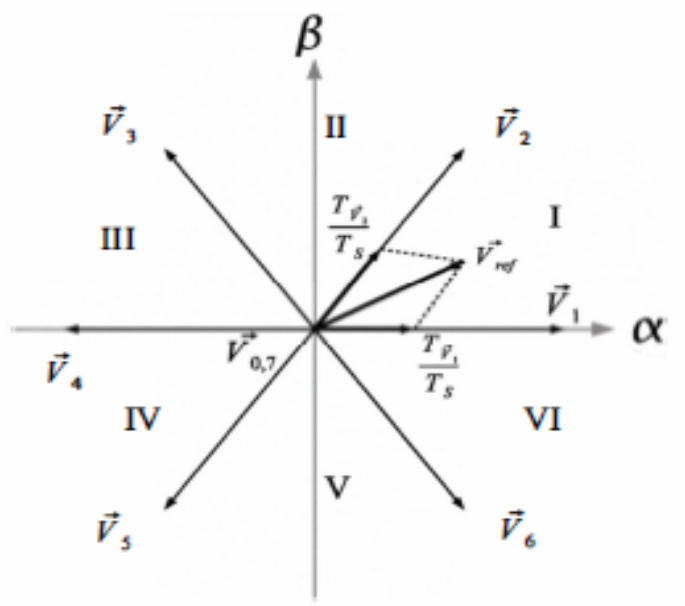

FIG. 2. THE SVPWM BASE VECTORS AND SECTORS IN $\alpha \beta$ FRAME. 


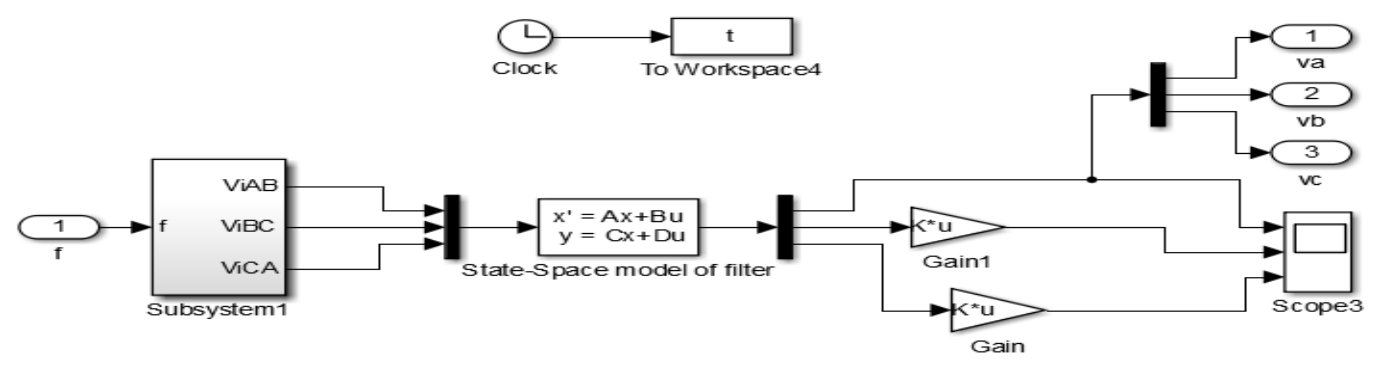

(A)

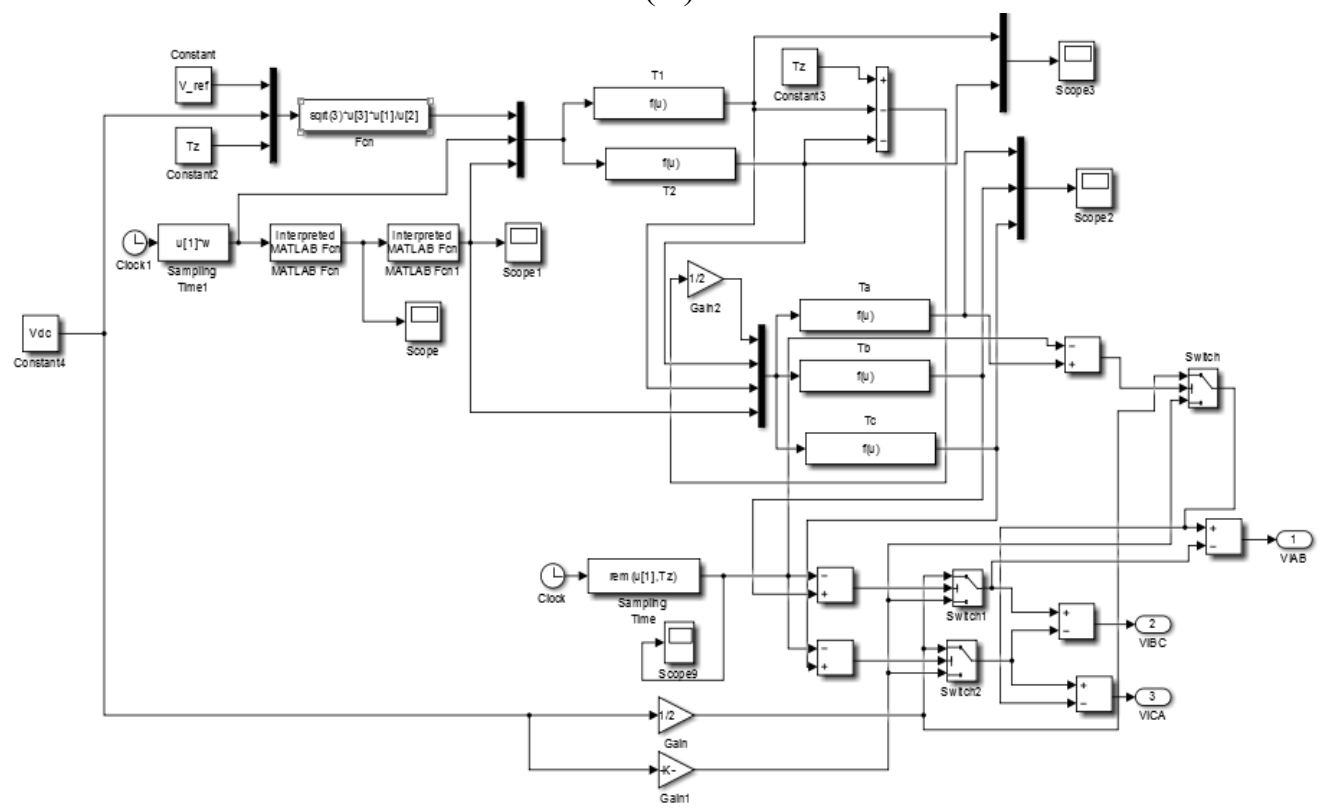

(B)

FIG. 3. A) THE SVPWM SIMULATION MODEL.

B) THE SIMULATION INSIDE (SUBSYSTEM1) BLOCK.

\section{MATHEMATICAL MODEL OF PMSM}

The voltage equations of the fourth order Three-phase PMSM in the rotating reference frame (d-q reference frame) are derived from the equivalent circuit below[3]:

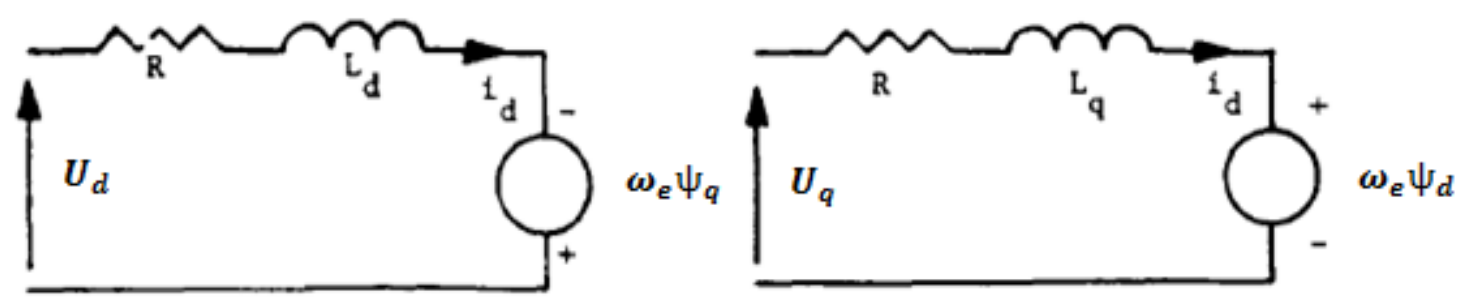

FIG. 4. PMSM EQUIVALENT CIRCUIT.

$$
\begin{aligned}
& U_{d}=R_{s} i_{d}+\frac{d \Psi_{d}}{d t}-\omega_{e} \psi_{q} \\
& U_{q}=R_{s} i_{q}+\frac{d \psi_{q}}{d t}+\omega_{e} \psi_{d}
\end{aligned}
$$


Where

$$
\psi_{d}=L_{d} i_{d}+\psi_{f}
$$

and

$$
\Psi_{q}=\boldsymbol{L}_{q} \boldsymbol{i}_{q}
$$

Rearrange these two voltage equations (3) and (4), the axis currents, electromagnatic torque, angular speed are given by[4]:

$$
\begin{aligned}
& T_{e}=\frac{3}{2} \frac{N_{p}}{2}\left[\psi_{f} i_{q}+\left(L_{d}-L_{q}\right) i_{d} i_{q}\right] \\
& \frac{d i_{d}}{d t}=-\frac{R_{s}}{L_{d}} i_{d}+\omega_{e} \frac{\left(L_{q} i_{q}\right)}{L_{d}}+\frac{1}{L_{d}} U_{d} \\
& \frac{d i_{q}}{d t}=-\frac{R_{s}}{L_{q}} i_{q}-\omega_{e} \frac{\left(L_{d} i_{d}+\psi_{f}\right)}{L_{q}}+\frac{1}{L_{q}} U_{q} \\
& \frac{d \omega_{r}}{d t}=\frac{T_{e}-T_{m}-F \omega_{r}}{J} \\
& \omega_{e}=\frac{N_{p}}{2} \omega_{r}
\end{aligned}
$$

From equations (7) - (11) the PMSM Simulink model is developed, and it is shown in Fig. 5.

(a)

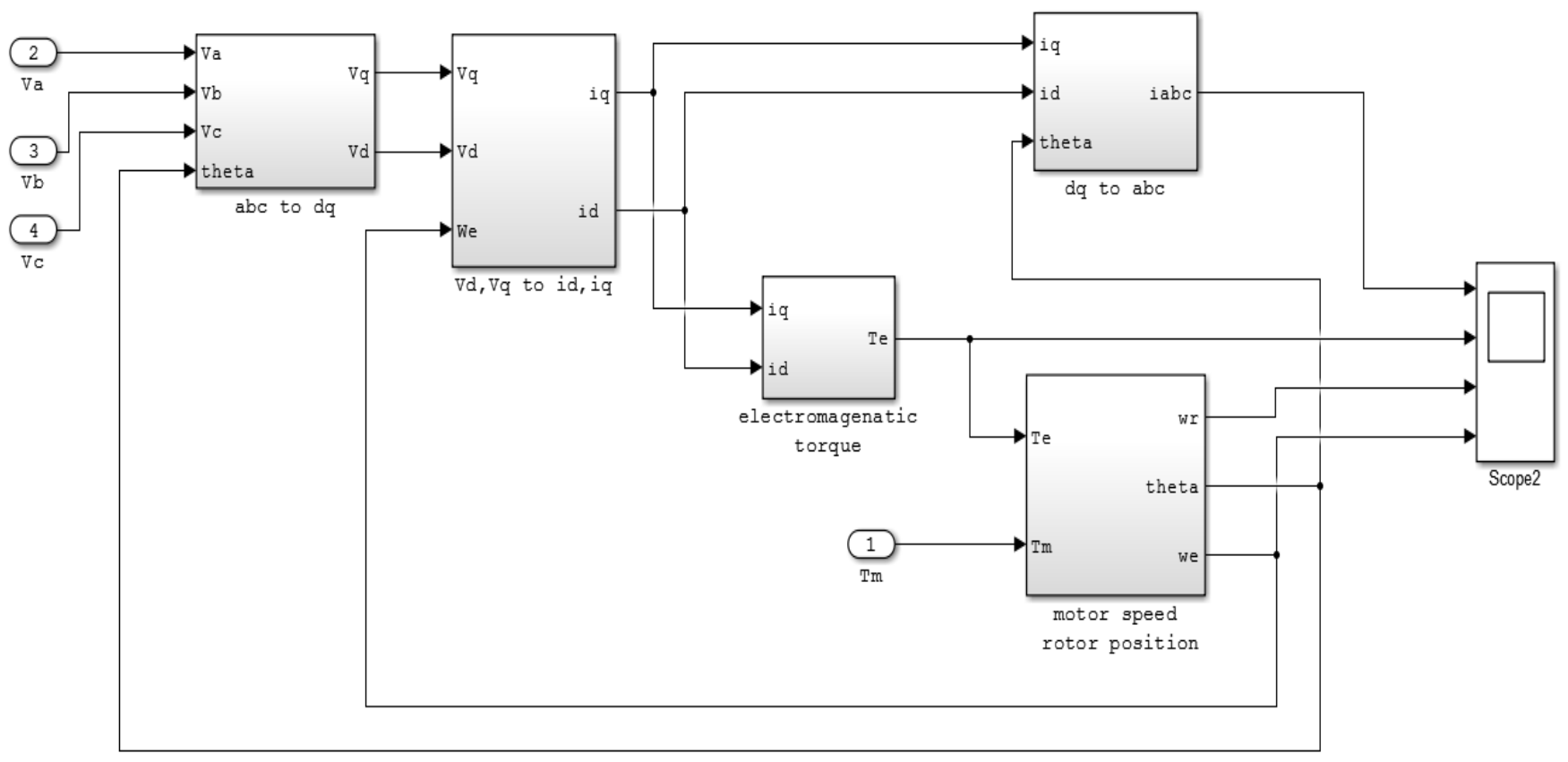

(b) 


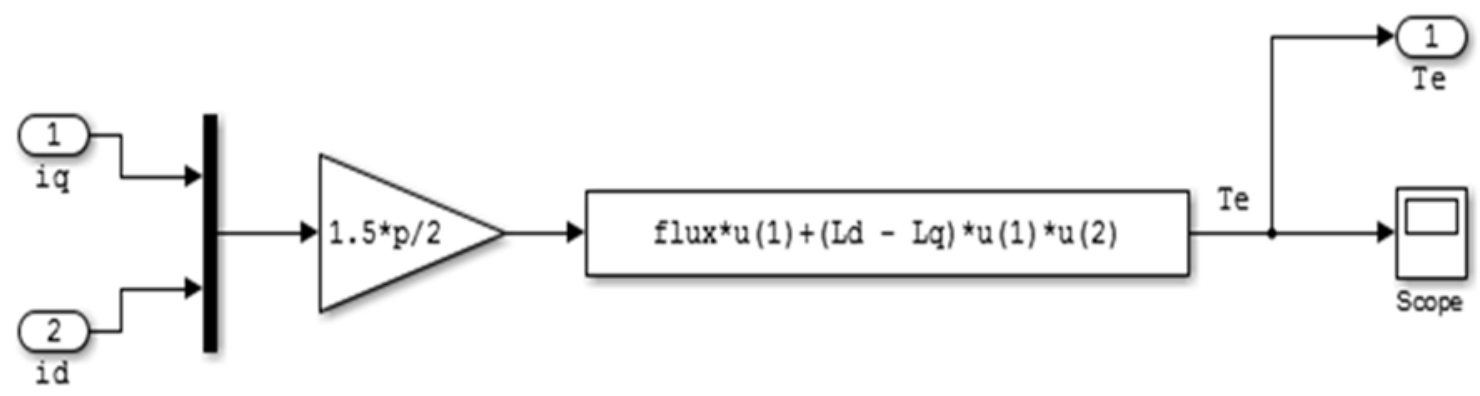

(c)

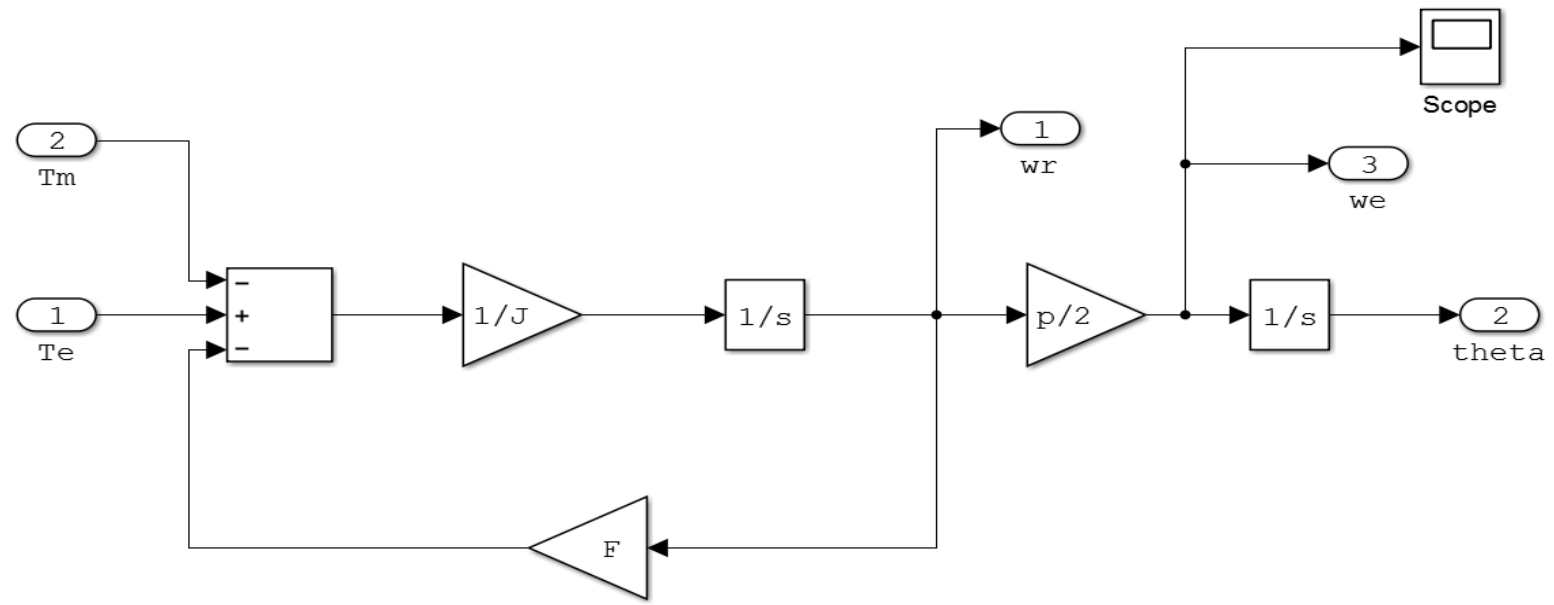

(d) 


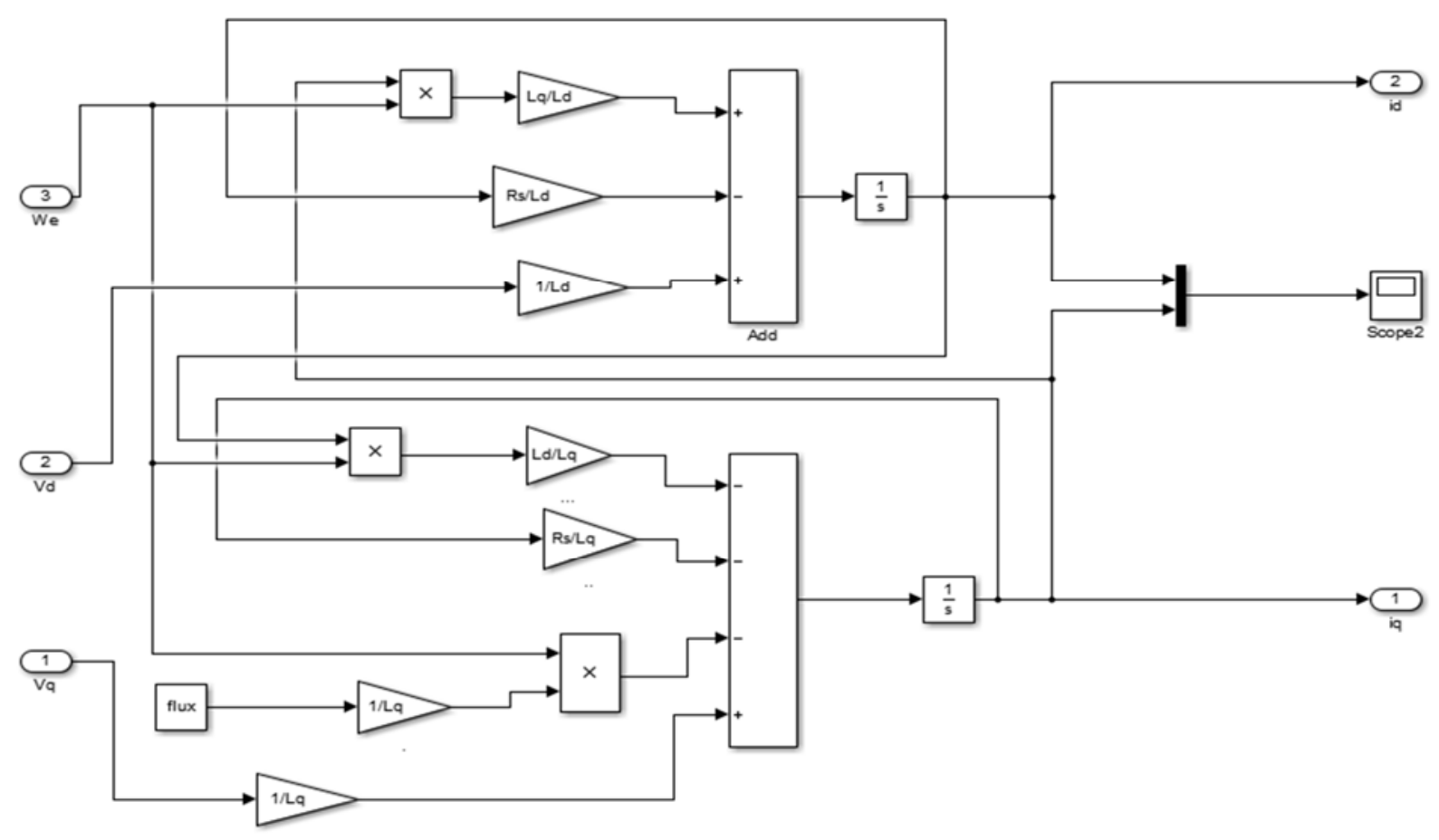

(e)

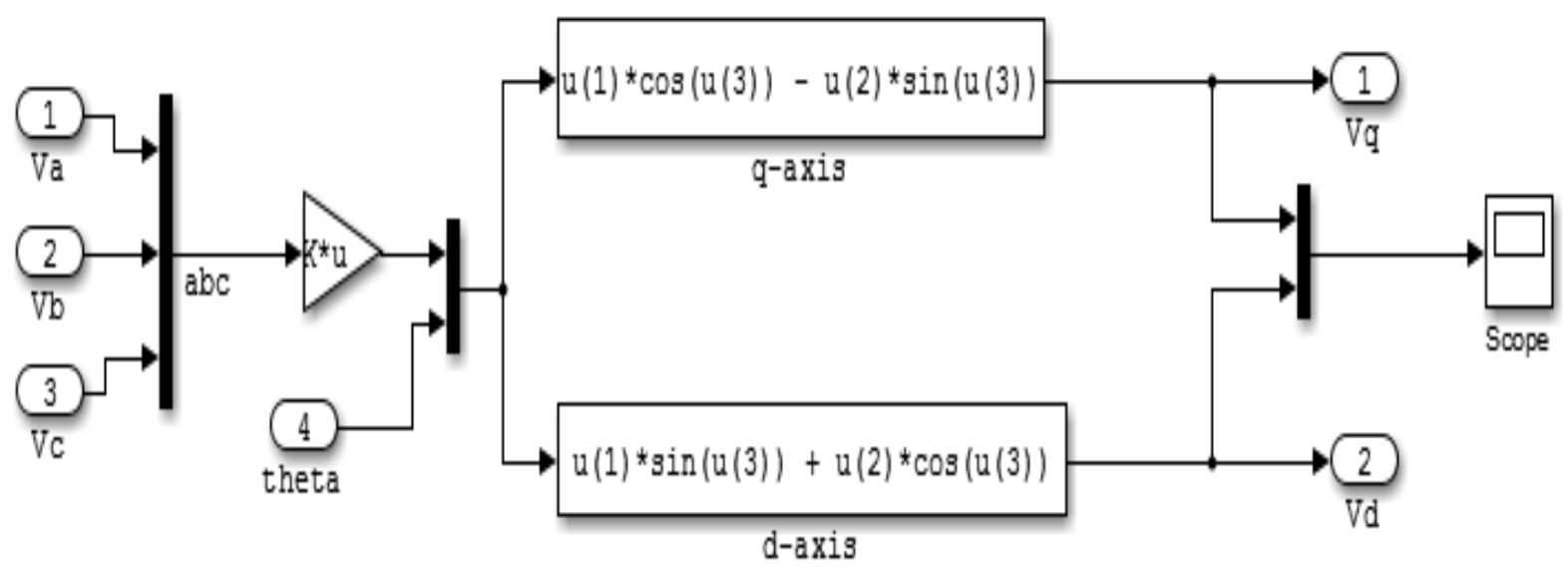

(f) 


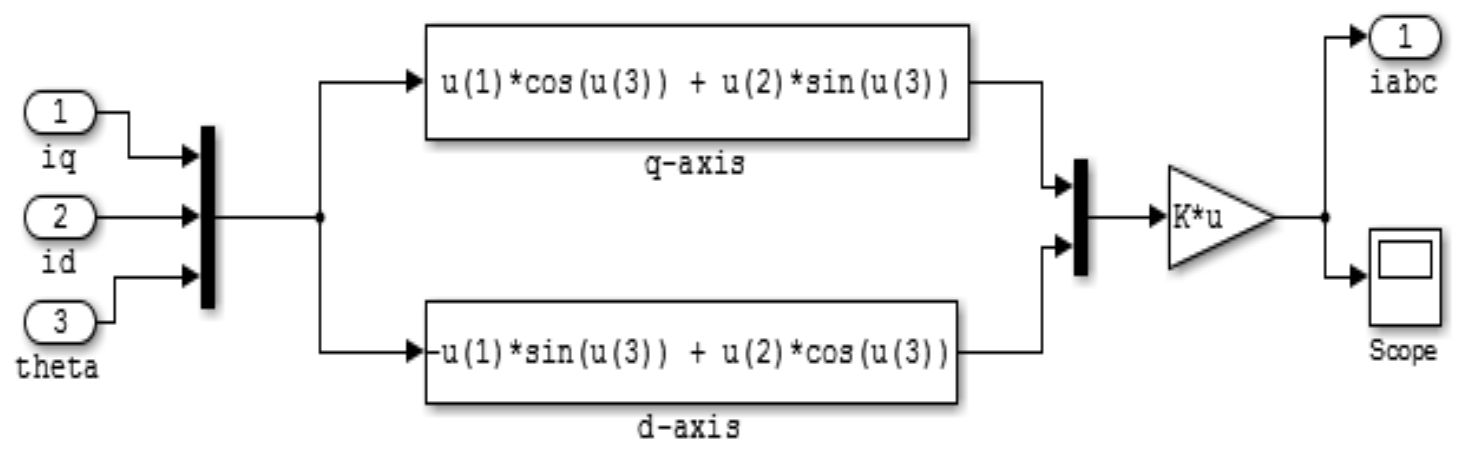

FIG 5. THE SIMULATION MODEL OF THE PERMANENT MAGNET SYNCHRONOUS MOTOR (PMSM )

(a) THE OPEN LOOP MODEL.

(b) ) INSIDE THE (ELECTROMAGNETIC TORQUE) BLOCK.

(c) INSIDE THE (MOTOR SPEED AND ROTOR POSITION ) BLOCK.

(d )INSIDE THE( $\mathrm{V}_{\mathrm{d}}, \mathrm{V}_{\mathrm{q}}$ TO $\left.\mathrm{i}_{\mathrm{d}}, \mathrm{i}_{\mathrm{q}}\right)$ BLOCK.

(e) INSIDE THE (abc TO dq) BLOCK.

(f) INSIDE THE (dq TO abc) BLOCK.

\section{STATE ESTIMATION WITH EKF:}

The model of the PMSM in the stationary reference frame $\left(\alpha \_\beta\right)$ is derived from the voltage equations below [5]and[6]:

$$
\begin{aligned}
& U_{\alpha}=R_{s} i_{\alpha}+L_{s} \frac{d i_{\alpha}}{d t}-\omega_{r} \Psi_{f} N_{p} \sin \left(\theta_{e}\right) \\
& U_{\beta}=R_{s} i_{\beta}+L_{s} \frac{d i_{\beta}}{d t}+\omega_{r} \psi_{f} N_{p} \cos \left(\theta_{e}\right)
\end{aligned}
$$

From these two voltage equations (12) and (13) the stator current, the mechanical speed and the electical position are:

$$
\begin{aligned}
& \frac{d i_{\alpha}}{d t}=-\frac{R_{s}}{L_{s}} i_{\alpha}+\omega_{r} \frac{\Psi_{f} N_{p}}{L_{s}} \sin \left(\theta_{e}\right)+\frac{1}{L_{s}} U_{\alpha} \\
& \frac{d i_{\beta}}{d t}=-\frac{R_{s}}{L_{s}} i_{\beta}-\omega_{r} \frac{\Psi_{f} N_{p}}{L_{s}} \cos \left(\theta_{e}\right)+\frac{1}{L_{s}} U_{\beta} \\
& \frac{d \omega_{r}}{d t}=0 \\
& \frac{d \theta_{e}}{d t}=\omega_{r}
\end{aligned}
$$


From the equations ( 14$)-(17)$, we have the state equation and output equation of PMSM in equations (18) and (19):

$$
\begin{aligned}
& \frac{d x}{d t}=A x+B u \\
& y=H x
\end{aligned}
$$

Defining

$$
\begin{gathered}
x=\left[\begin{array}{c}
i_{\beta} \\
\omega_{r} \\
\theta_{e}
\end{array}\right], \quad U=\left[\begin{array}{c}
U_{\alpha} \\
U_{\beta}
\end{array}\right], \quad Y=\left[\begin{array}{l}
i_{\alpha} \\
i_{\beta}
\end{array}\right], \\
A=\left[\begin{array}{cccc}
-\frac{R_{s}}{L_{s}} & 0 & \frac{\psi_{f} N_{p}}{L_{s}} \sin \left(\theta_{e}\right) & 0 \\
0 & -\frac{R_{s}}{L_{s}} & \frac{\psi_{f} N_{p}}{L_{s}} \cos \left(\theta_{e}\right) & 0 \\
0 & 0 & 0 & 0 \\
0 & 0 & N_{p} & 0
\end{array}\right], \quad B=\left[\begin{array}{ll}
\frac{1}{L_{s}} & 0 \\
0 & \frac{1}{L_{s}} \\
0 & 0 \\
0 & 0
\end{array}\right], \quad H=\left[\begin{array}{llll}
1 & 0 & 0 & 0 \\
0 & 1 & 0 & 0
\end{array}\right] .
\end{gathered}
$$

The discrete equations of (18) and (19) can be written as [5]:

$$
\begin{aligned}
\tilde{x}_{k} & =f\left(\widehat{x}_{k-1}, u_{k-1}\right) \\
y_{k} & =h\left(x_{k}\right)
\end{aligned}
$$

Where

$$
\begin{gathered}
f\left(\widetilde{x}_{k-1}, u_{k-1}\right)=(I+A . T) \widehat{x}_{k-1}+B . T \cdot u_{k-1} \\
y_{k}=H \cdot \widehat{x}_{k-1}
\end{gathered}
$$

The system matrix can be defined as:

$$
\phi_{k}=\left[\begin{array}{cccc}
1-T \frac{R_{s}}{L_{s}} & 0 & T \frac{\Psi_{f} N_{p}}{L_{s}} \sin \left(\theta_{e}\right) & T \frac{\Psi_{f} N_{p}}{L_{s}} \omega_{r} \cos \left(\theta_{e}\right) \\
0 & 1-T \frac{R_{s}}{L_{s}} & -T \frac{\psi_{f} N_{p}}{L_{s}} \cos \left(\theta_{e}\right) & T \frac{\psi_{f} N_{p}}{L_{s}} \omega_{r} \sin \left(\theta_{e}\right) \\
0 & 0 & 1 & 0 \\
0 & 0 & T & 0
\end{array}\right]
$$


The flow chart as shown in Fig. 6 Represents the computing cycle of the Extended Kalman Filter which consist of two steps (Prediction and Correction) with the equations of these two steps where the Extended Kalman Filter model is built based on these equations with the appropriate Values of Q and $\mathrm{R}$ to obtain the desired stable and accurate estimated results.

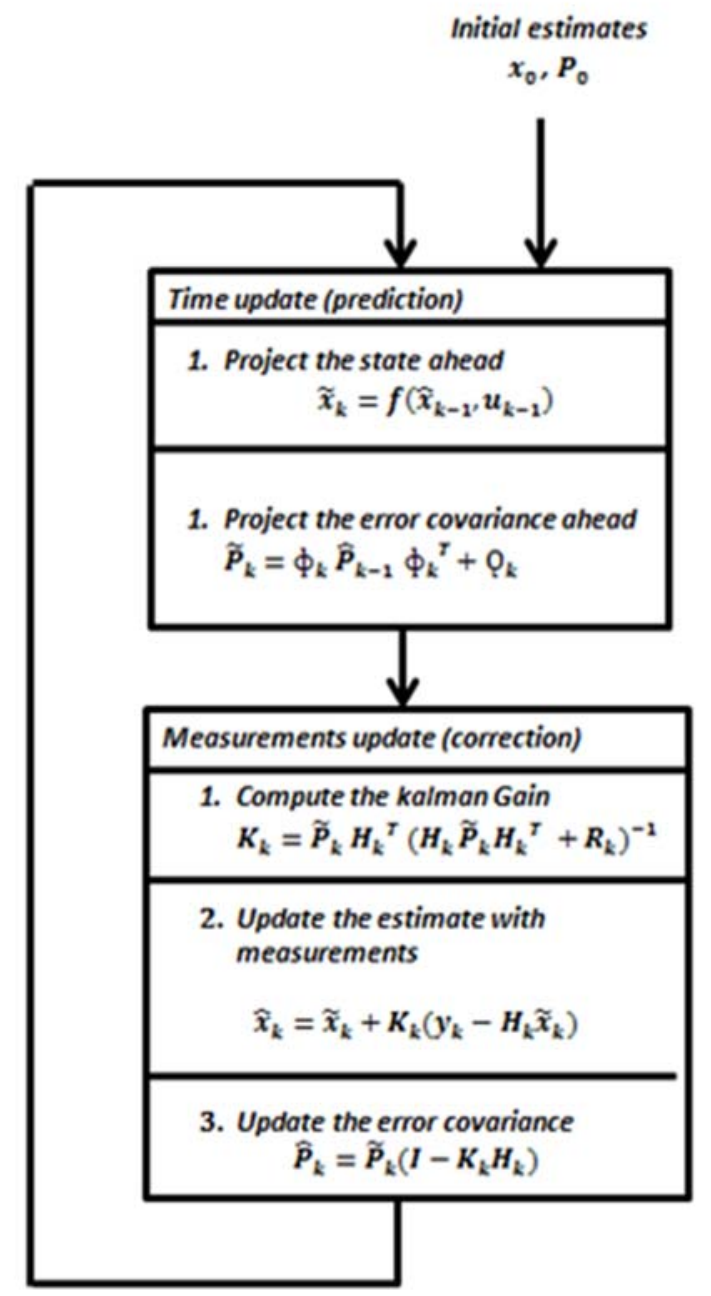

FIG 6. THE FLOW CHART OF AN EKF ESTIMATOR.

\section{FUZZY LIKE PI CONTROLLER DESIGN:}

The structure of the FLC[7] is shown in Fig. 7 and the base rules required for computing the output are listed in TABLE 1 . The output of the controller represents the frequency which indicates the speed of the PMSM. A trial and error technique is used to tune the controller gains $(\mathrm{Kp}, \mathrm{Kd})$ to obtain the desired performance. 


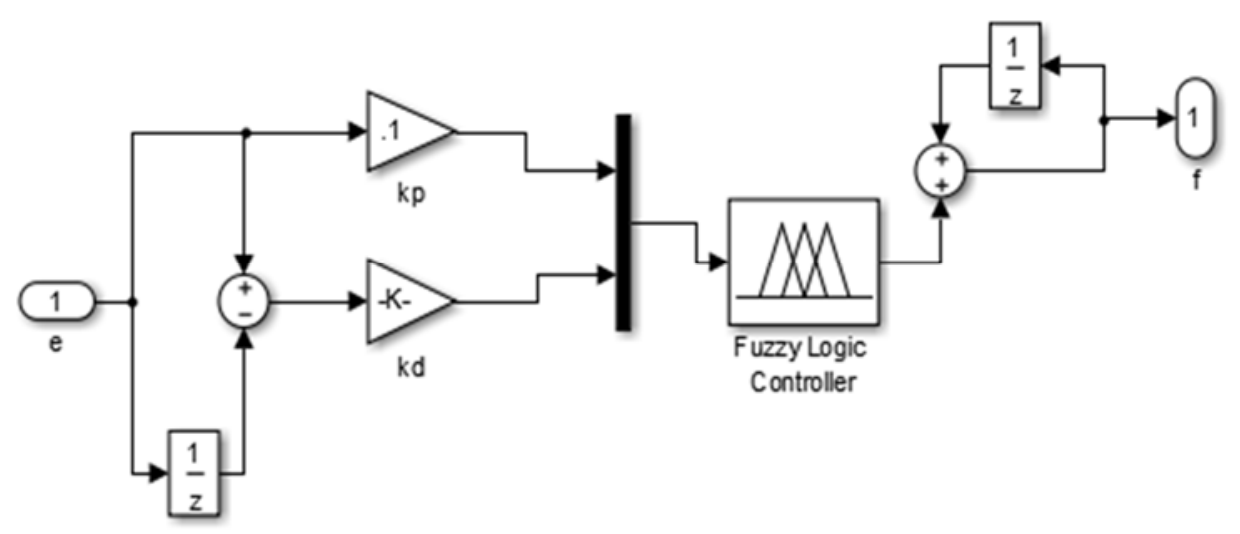

FIG. 7. THE STRUCTURE OF THE FUZZY LOGIC CONTROLLER.

TABLE .1. The base rules of the FLC.

a)

\begin{tabular}{|c|c|c|c|c|c|c|c|}
\hline e $/ \dot{e}$ & NB & NM & NS & $\mathbf{Z}$ & PS & PM & PB \\
\cline { 1 - 4 } NB & PB & PB & PB & PB & PM & PS & Z \\
\hline NM & PB & PB & PB & PM & PS & Z & NS \\
\hline NS & PB & PB & PM & PS & Z & NS & NM \\
\hline Z & PB & PM & PS & Z & NS & NM & NB \\
\hline PS & PM & PS & Z & NS & NM & NB & NB \\
\hline PM & PS & Z & NS & NM & NB & NB & NB \\
\hline PB & Z & NS & NM & NB & NB & NB & NB \\
\hline
\end{tabular}

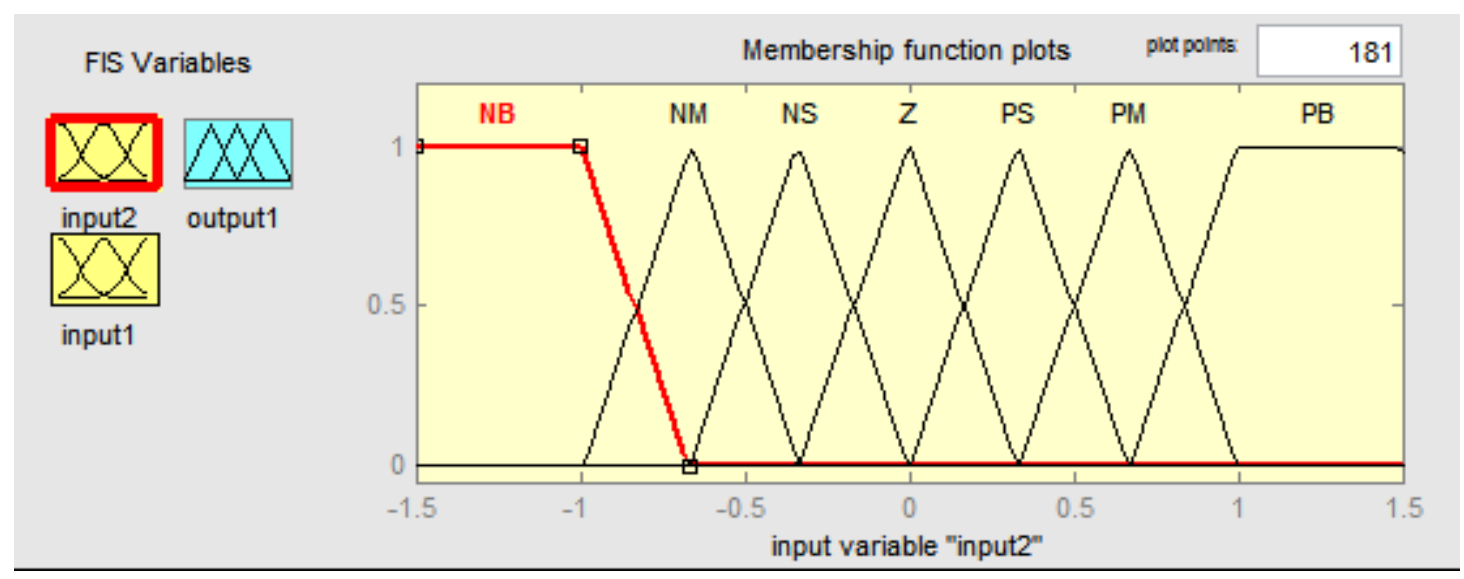

b) 


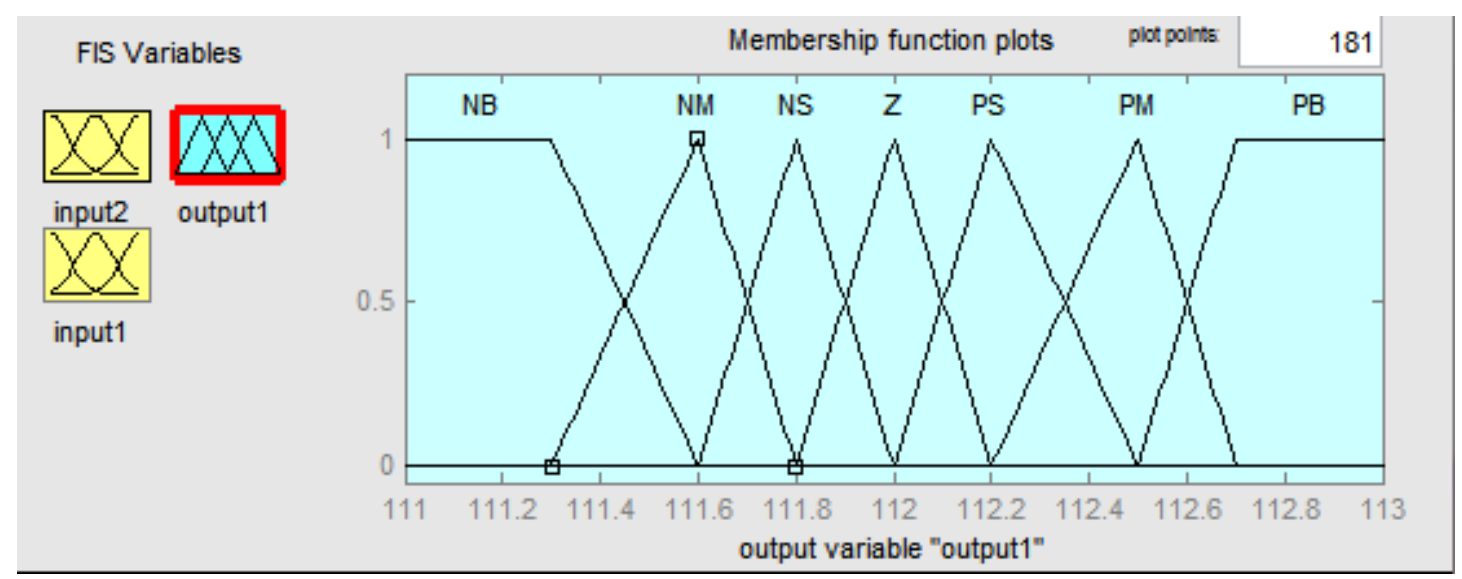

FIG. 8. a) MEMBERSHIP FUNCTIONS FOR INPUT VARIABLES e AND e .

b) MEMBERSHIP FUNCTIONS FOR OUTPUT VARIABLE.

\section{SIMULATION RESULTS}

To control the speed of a three phase Permanent Magnet Synchronous Motor closed loop system using the Field Oriented Control strategy the simulation model is established with Matlab/Simulink program and parameters used in this model are shown in Table.2.[4]

TABLE 2. PARAMETERS OF PMSM

\begin{tabular}{|c|c|c|}
\hline Parameters & Values & Units \\
\hline Stator Resistance $\left(R_{s}\right)$ & 2.875 & $\Omega$ \\
\hline $\begin{array}{c}\text { Inductance } \\
\left(L_{d}=L_{q}=L_{s}\right)\end{array}$ & 0.0085 & $\mathrm{H}$ \\
\hline Induced Flux $\left(\Psi_{f}\right)$ & 0.175 & $\mathrm{~Wb}$ \\
\hline Friction Factor $(\mathrm{F})$ & 0 & $\mathrm{Kg} * \mathrm{~m}^{2}$ \\
\hline Inertia $(\mathrm{J})$ & 0.0008 & none \\
\hline Pairs of poles $(\mathrm{Np})$ & 4 & \\
\hline
\end{tabular}

The initialization required for the initial state and state error covariance matrix are $\mathrm{x}=[0 ; 0 ; 0 ; 0]$, $\mathrm{P}=\operatorname{diag}\left(\left[\begin{array}{llll}1 & 1 & 100 & 10\end{array}\right]\right)$;. Varying the value of the covariance matrix $\mathrm{P}$ may affect either the system performance or the system steady state condition. In this research, the values of the covariance matrix tuned manually by running several simulations, and this is one of the major drawbacks of the Kalman filtering. Another drawback and critical step in the EKF is to search for the best value of covariance 
matrices $\mathrm{Q}$ and $\mathrm{R}$ with out making the estimates too noisy, the values set up was by trail-error procedure.

$\mathrm{Q}=\operatorname{diag}\left(\left[\begin{array}{llll}20 & 20 & 0.001 & 0.11\end{array}\right]\right) ;$

$\mathrm{R}=\operatorname{diag}\left(\left[\begin{array}{ll}0.5 & 0.5\end{array}\right]\right)$

In the EKF algorithm the kalman gain calculation depends on $\mathrm{P}, \mathrm{Q}$ and $\mathrm{R}$, where $\mathrm{Q}$ represents the covariance matrix of system noise and $\mathrm{R}$ represents the covariance matrix of the observation noise.The values of $q_{11}, q_{22}, q_{33}, q_{44}$ in $\mathrm{Q}=\operatorname{diag}\left(\left[q_{11} ; q_{22} ; q_{33} ; q_{44}\right]\right)$ affects the performance of the EKF.

Fig. 9, Fig. 10 and Fig. 11 show the responses of the measured and estimated state variables (the angular speed, rotor position, and stator currents) via the EKF for step reference of $176 \mathrm{rad} / \mathrm{s}$ with a load torque applied at time $\mathrm{t}=0.3 \mathrm{~s}$.

As we can see the estimated states are capable of tracking the actual one and they meet the requirements of our control system. It's very important to know that the sampling rate for the limitations of the EKF is $1 \mathrm{~ms}$ for measurements. If the sample time decreases, the EKF estimate will be reversed and the EKF becomes unstable. 


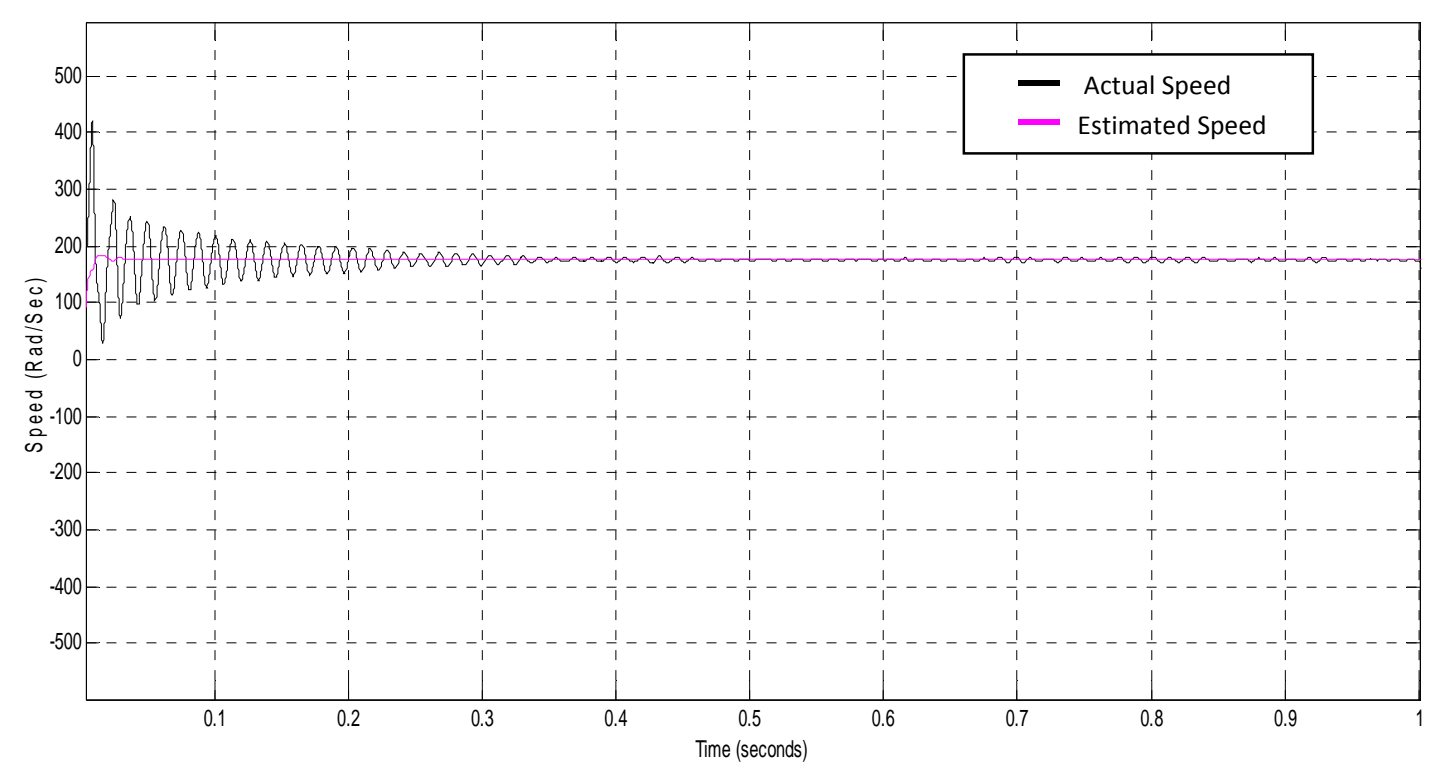

FIG. 9. THE SIMULATION RESULTS OF THE SPEED.

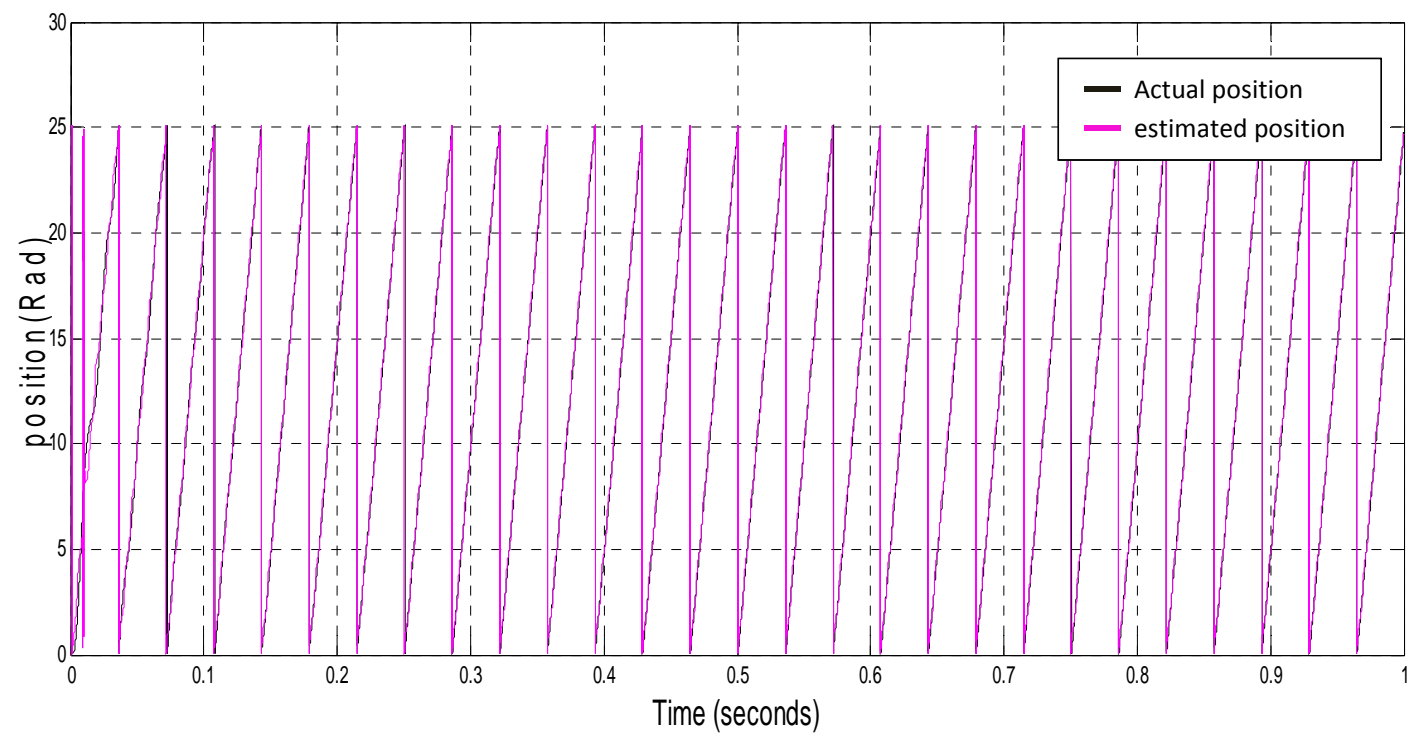

FIG. 10. THE SIMULATION RESULT OF ROTOR POSITION. 


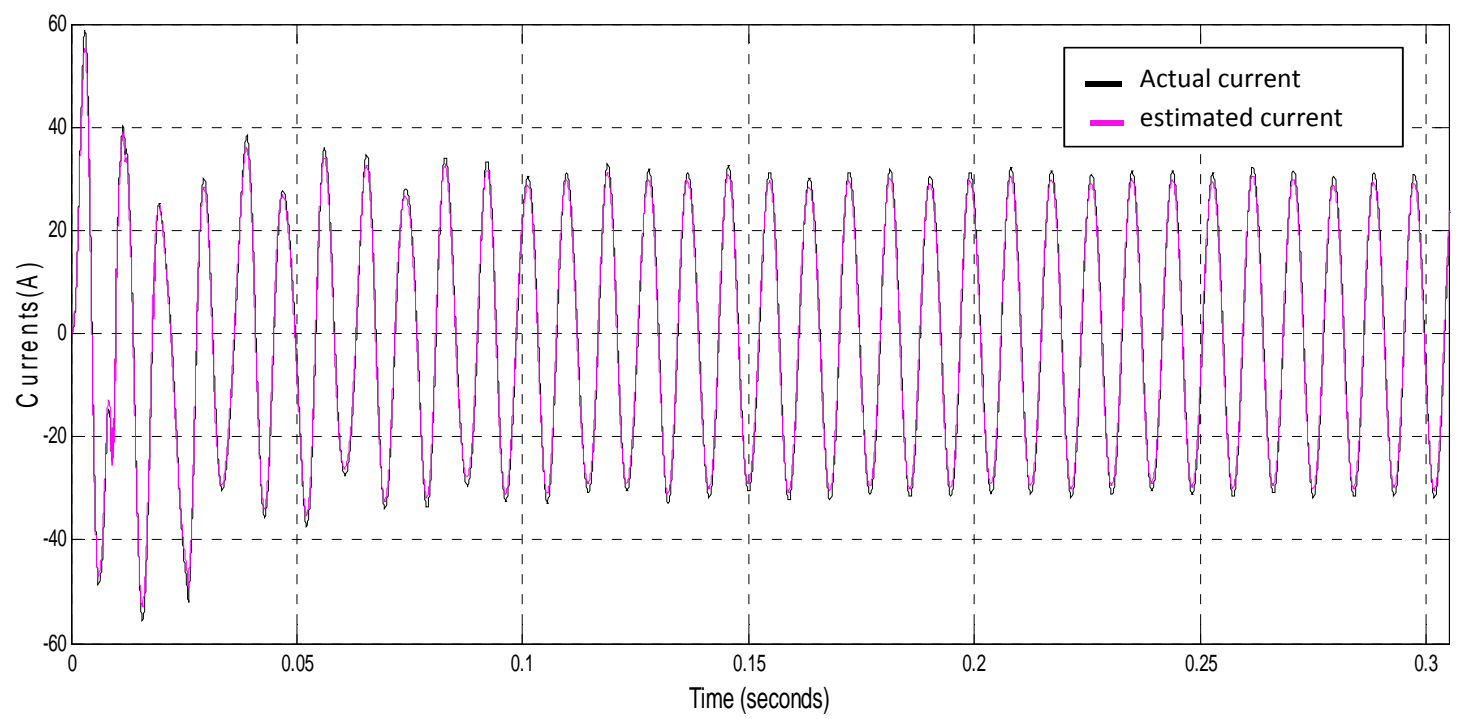

FIG. 11. THE SIMULATION RESULTS OF THE CURRENTS ( $\alpha \beta$ CURRENTS).

The estimation of the Kalman gain tells how much we need to change the estimate with the given measurement.

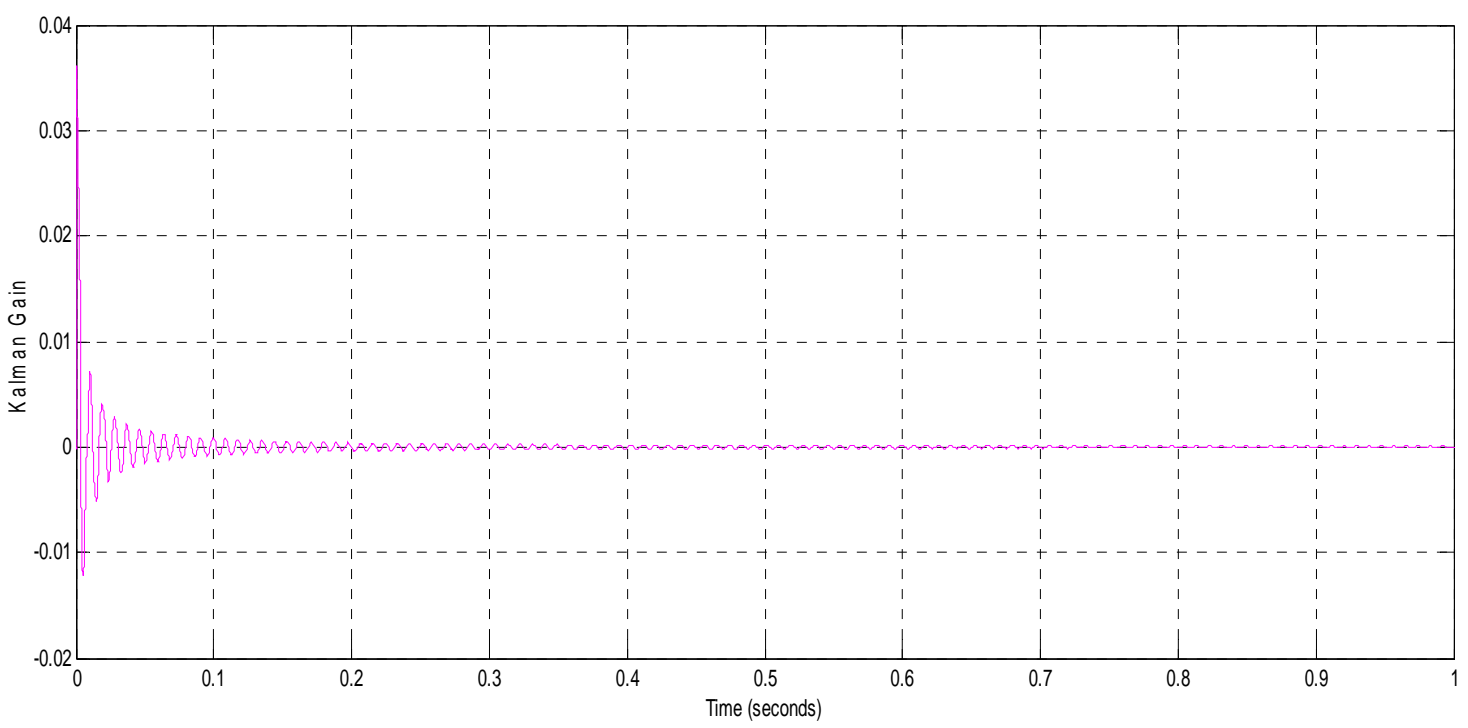

FIG. 12. THE SIMULATION RESULT OF THE KALMAN GAIN FOR THE SPEED.

The results of the error covariance indicates the accuracy of the Extended Kalman Filter as an estimator as we see the error decreases gradually untile it becomes zero or a small value near to zero. If the covariance is not as expexted this means that there is some thing wrong with the filter. 
a)

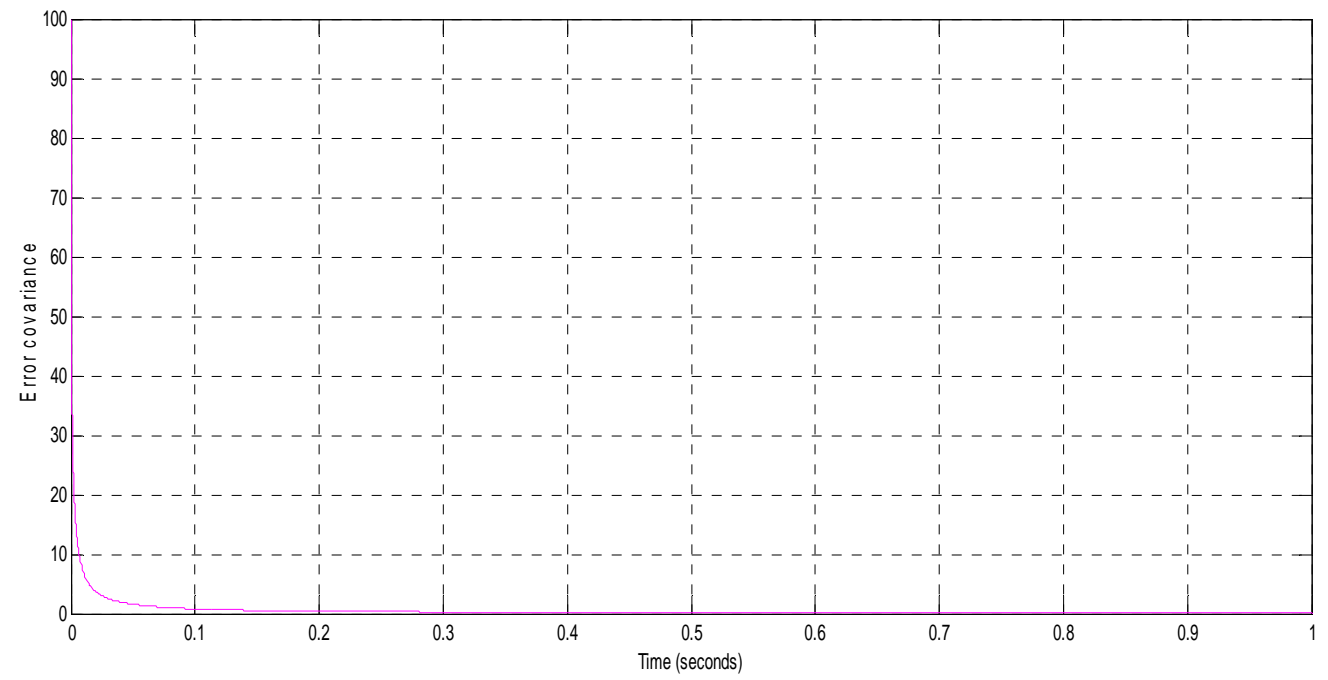

b)

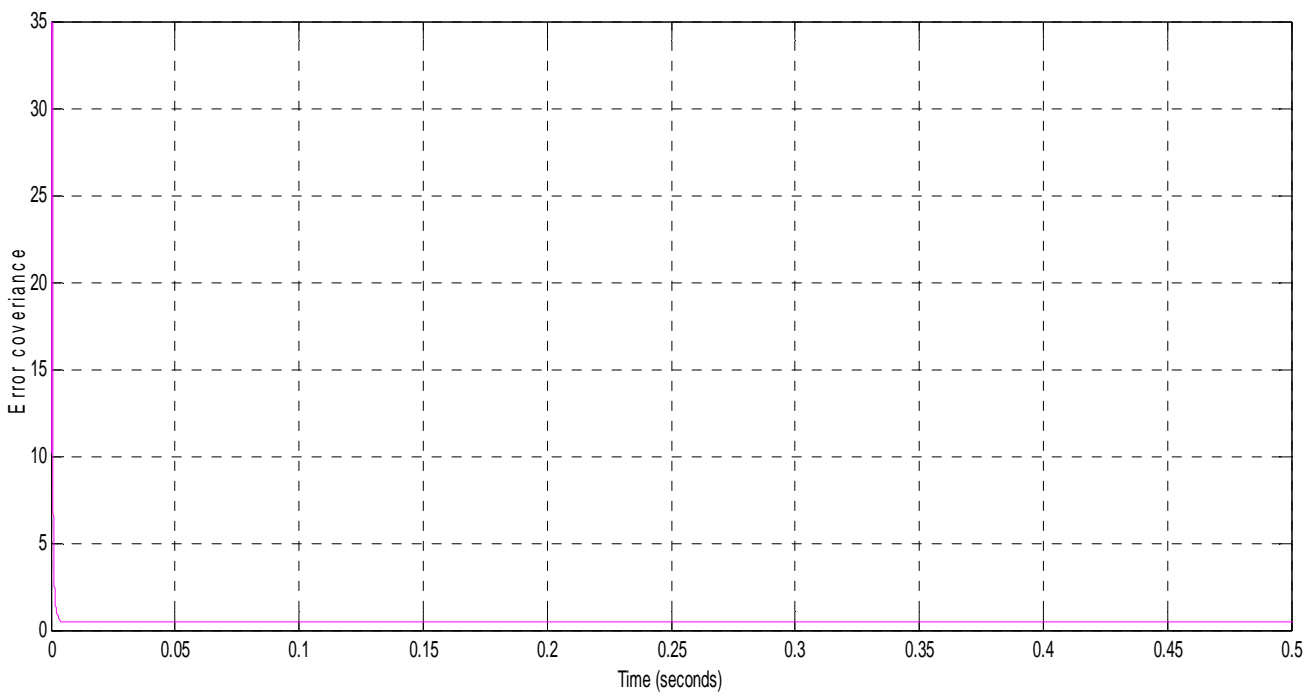

FIG.13. THE SIMULATION RESULT OF THE ERROR COVARIANCE

a) THE SPEED ERROR COVARIANCE.

b) THE POSITION ERROR COVARIANCE.

a)

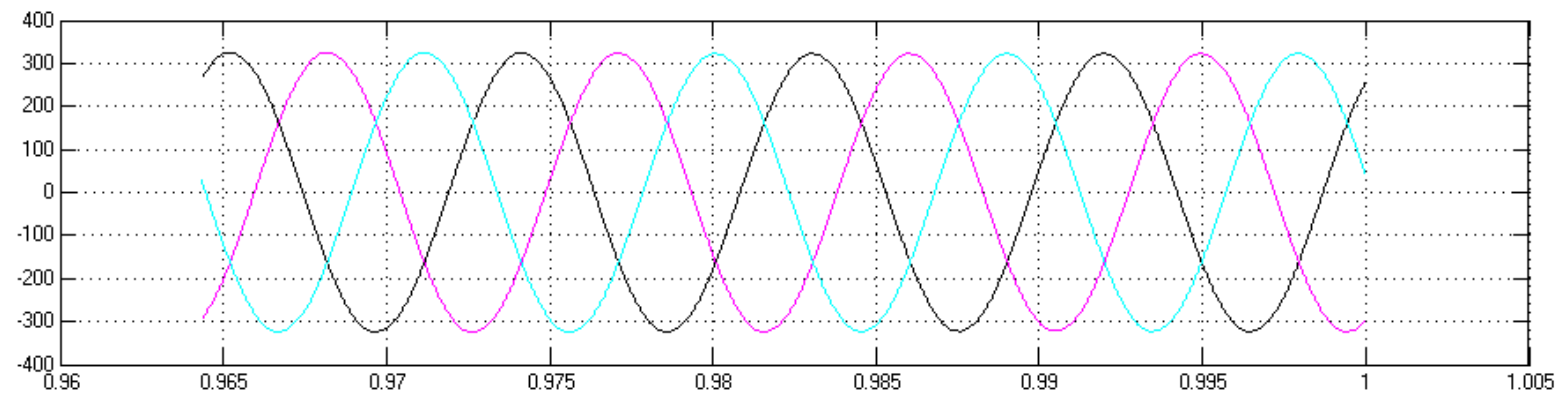

Received 20 Feb 2018; Accepted 9 May 2018 
b)

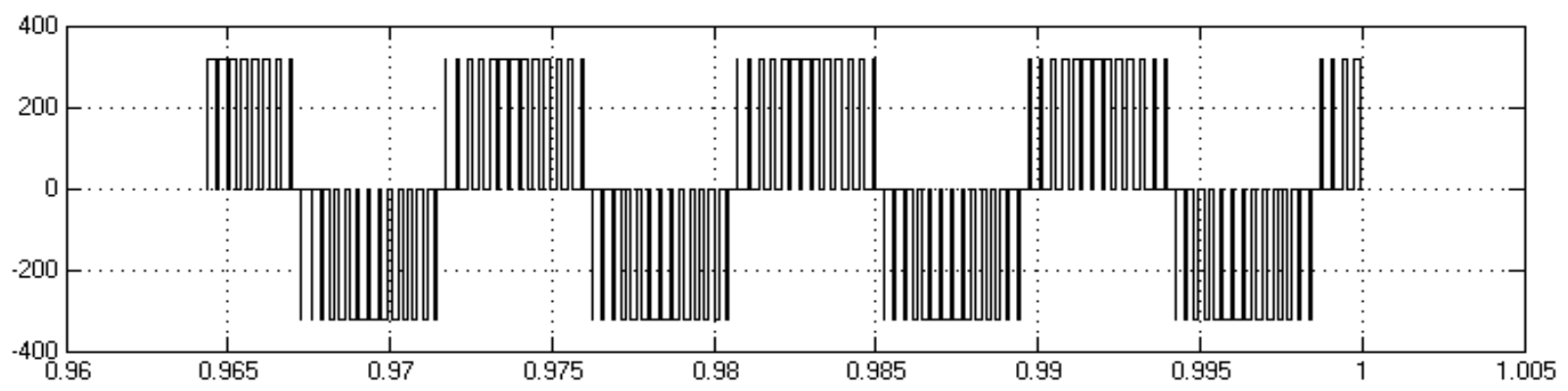

c)

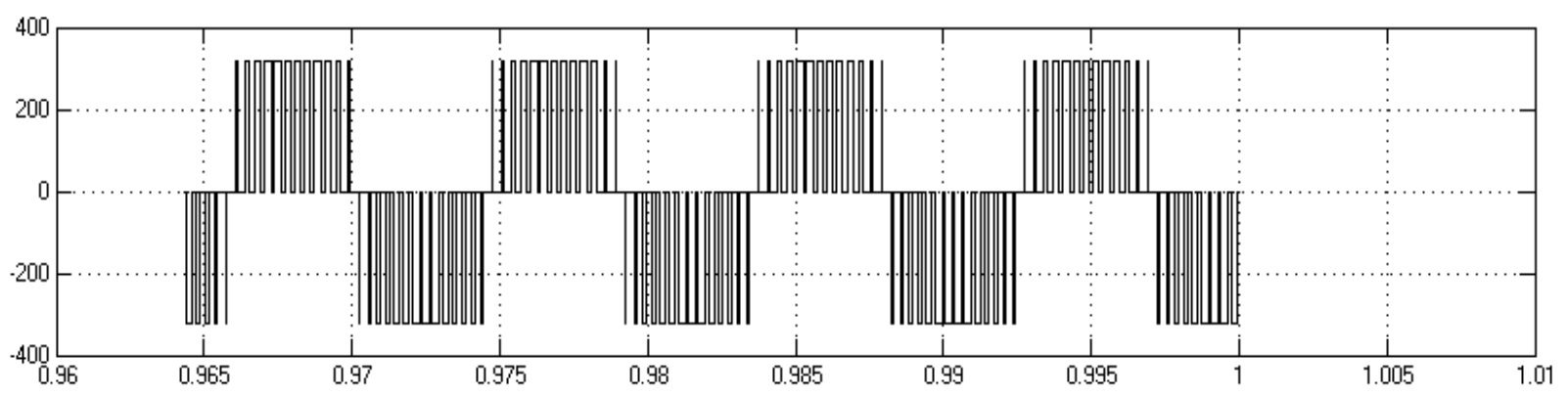

d)

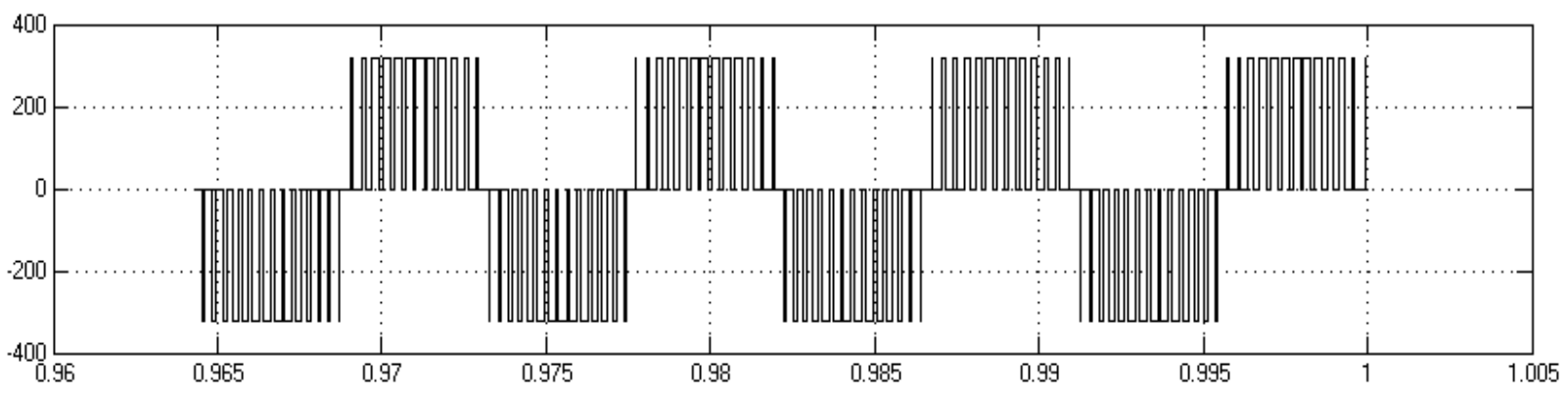

FIG. 14. SIMULATION WAVEFORMS OF SVPWM INVERTER.

a) THE THREE PHASE VOLTAGE (Va, Vb, Vc).

b) INVERTER OUTPUT $V_{\text {iAB }}$ BEFORE FILTERING.

c) INVERTER OUTPUT $V_{\text {iBC }}$ BEFORE FILTERING.

d) INVERTER OUTPUT $V_{\text {iCA }}$ BEFORE FILTERING. 


\section{CONCLUSION}

The performance of the sensorless speed estimation of the PMSM using FOC strategy with an EKF was studied. When the load torque applied at time $t=0.3 \mathrm{~s}$ the speed is disturbed and then it becomes stable, this is due to the nature of the motor that runs with synchronous speed $N_{s}$ only. The estimated speed $\widehat{\boldsymbol{\omega}}_{\boldsymbol{r}}$ by the EKF by using measurements of the motor currents only is compared with reference speed $\omega_{r}{ }^{*}$ the resulting speed error (e) is fed into FLC with seven triangular membership functions to produce the frequency required for the PMSM. The PWM voltage source inverter generates the three phase voltages with a phase shift of $120^{\circ}$ and 320 volt amplitude. The simulation results showed the feasibility of the filter for the estimation of the PMSM state vector also its robustness against the noise through reducing the error to minimum values and this results the great compatibility between the estimated and the actual states. Several simulation results have been presented such as the kalman gain and the error covariance for the speed and position to show the effectiveness of the Estimator the most important thing is knowing the values of $\mathrm{Q}$ and $\mathrm{R}$ whenever they were accurate this indicates the filter effectiveness.

\section{NOMENCLATURE}

$\begin{array}{ccc}\text { symbol } & \text { Definition } & \text { Units } \\ \mathbf{F} & \text { Friction coefficient } & \\ \mathbf{f} & \text { frequency } & \text { None } \\ \boldsymbol{i}_{\boldsymbol{d}}, \boldsymbol{i}_{\boldsymbol{q}} & \text { d-q axis stator currents in the rotor reference frame } & \text { Hertz } \\ \boldsymbol{i}_{\boldsymbol{\alpha}}, \boldsymbol{i}_{\boldsymbol{\beta}} & \alpha-\beta \text { axis stator currents in the stationary reference frame } & \text { Amperes } \\ \mathbf{J} & \text { moment of inertia } & \text { Amperes } \\ \boldsymbol{L}_{\boldsymbol{d}}, \boldsymbol{L}_{\boldsymbol{q}} & \text { d- q axis inductances } & \text { Kg } * \mathrm{~m}^{2} \\ \boldsymbol{L}_{\boldsymbol{s}} & \text { Stator winding self-inductance } & \text { henry } \\ \boldsymbol{N}_{\boldsymbol{p}} & \text { Number of pole pairs } & \text { henry } \\ \mathbf{P} & \text { state error covariance matrix } & \text { none } \\ \mathbf{Q} & \text { the covariance matrix of system noise } & \text { none } \\ \boldsymbol{R} & \text { the covariance matrix of the observation noise } & \text { none } \\ \boldsymbol{R}_{\boldsymbol{s}} & \text { Stator resistance } & \text { none } \\ \boldsymbol{T}_{\boldsymbol{e}} & \text { Electromagnetic torque } & \text { ohms } \\ \boldsymbol{T}_{\boldsymbol{m}} & \text { Motor load torque } & \text { newton meters } \\ \boldsymbol{U}_{\boldsymbol{a}}, \boldsymbol{U}_{\boldsymbol{b}}, \boldsymbol{U}_{\boldsymbol{c}} & \text { Phase a, b and c rotor voltages } & \text { newton meters } \\ \boldsymbol{U}_{\boldsymbol{d}}, \boldsymbol{U}_{\boldsymbol{q}} & \text { d- q axis voltages in the rotor reference frame } & \text { volts } \\ \boldsymbol{U}_{\boldsymbol{\alpha}}, \boldsymbol{U}_{\boldsymbol{\beta}} & \alpha-\beta \text { axis stator voltages in the stationary reference } & \text { volts } \\ \Psi_{\boldsymbol{d}}, \Psi_{\boldsymbol{q}} & \text { The d-q axis flux-linkages } & \text { volts } \\ \Psi_{\boldsymbol{f}} & \text { Induced flux } & \text { webers } \\ \boldsymbol{\omega}_{\boldsymbol{r}} & \text { The mechanical angular speed } & \text { webers } \\ \boldsymbol{\omega}_{\boldsymbol{e}} & \text { The stator electrical angular speed } & \text { radians per second } \\ \boldsymbol{\theta}_{\boldsymbol{e}} & \text { Angular position } & \text { radians per second } \\ & & \text { radians }\end{array}$




\section{Acronyms}

\section{Acronyms}

$$
\begin{gathered}
\text { EKF } \\
\text { FLC } \\
\text { FOC } \\
\text { PMSM } \\
\text { PWM } \\
\text { SVPWM }
\end{gathered}
$$

\section{Definition}

\author{
Extended Kalman Filter \\ Fuzzy Logic Control \\ Field Oriented Control \\ Permanent Magnet Synchronous Motor \\ Pulse Width Modulation \\ Space-Vector Pulse Width Modulation
}

\section{REFERENCES}

[1] JIN-Woo Jung. "Project \#2 Space Vector PWM inverter". Project performed at Mechatronic Systems Laboratory, Department of Electrical and Computer Engineering, The Ohio State University, USA. 2005. Available at: http://www2.ece.ohio-state.edu/ems/PowerConverter/SpaceVector_PWM_Inverter.pdf.

[2] Nazlee AM, Hamid NH, Hussin FA and Ali NBZ. "Space Vector PWM for PMSM simulation using Matlab Simulink". IEEE Asia Pacific Conference on Circuits and Systems. 2010; 1127-1130.

[3] Pragasen Pillay and Ramu Krishnan, “Modeling of permanent magnet motor drives,"IEEE Trans.Ind. Electron. vol. 35, no. 4, pp. 537-541, Nov. 1988.

[4] Jixun Gao and Jianli Kang, "Modeling and Simulation of Permanent Magnet Synchronous Motor Vector Control", Information Technology Journal, 2014, 13: 578-582.

[5] Tao Xu and Zhengbin Zhang, "Simulation of Permanent Magnet Synchronous Motor Control System with Extended Kalman Filter", Journal of Theoretical and Applied Information Technology, 10th May 2013. Vol. 51 No .1.

[6] Yong Zhang and Xu-Feng Cheng, "Sensorless Control of Permanent Magnet Synchronous Motors and EKF Parameter Tuning Research," Mathematical Problems in Engineering, vol. 2016, Article ID 3916231, 12 pages, 2016. doi: $10.1155 / 2016 / 3916231$.

[7] Hanan Mikhael D. Habbi and Sara T. Rashed, "PI and Fuzzy Speed Controllers for PM Synchronous Motor Drive", International Journal of Computer Applications, September 2016 Volume 149 - No.1. 